\title{
Knowledge, attitudes and practices toward antimicrobial usage: a cross-sectional study of layer and pig farm owners/managers in Chiang Mai, Lamphun, and Chonburi provinces, Thailand, May 2014 to February 2016
}

\author{
Aniroot Nuangmek ${ }^{1,3}$, Suvichai Rojanasthien ${ }^{2}$, Prapas Patchanee ${ }^{2}$, Terdsak Yano ${ }^{2}$, Panuwat Yamsakul ${ }^{2}$, \\ Suwit Chotinun ${ }^{2}$, Pakpoom Tadee ${ }^{2, *}$ \\ ${ }^{1}$ Graduate Program in Veterinary Science, and ${ }^{2}$ Integrative Research Center for Veterinary Preventive Medicine, Department of \\ Food Animal Clinic, Faculty of Veterinary Medicine, Chiang Mai University, Chiang Mai 50100, Thailand \\ ${ }^{3}$ Phayao Provincial Livestock Office, Phayao 56000, Thailand
}

(Received: January 10, 2018; Revised: February 26, 2018; Accepted: March 8, 2018)

\begin{abstract}
This study aimed at determining the current knowledge, attitude, and practices (KAP) of layer and pig farmers to antimicrobial usage and its consequences. Description of such KAP could provide insights useful for promoting the rational use of antimicrobials in livestock. From May 2014 to February 2016, a survey involving 251 respondents in Chiang Mai, Lamphun, and Chonburi provinces, Thailand, was conducted by using a validated questionnaire. More than half $(51.0 \%)$ of the respondents incorrectly believed that antimicrobial drug efficacy could not be reduced by using sub-recommended dosages, $61.2 \%$ had misconceptions about non-therapeutic antimicrobial use, and $66.9 \%$ inaccurately felt that antimicrobials were also effective for virus and fungi. Over half $(50.6-55.2 \%)$ did not see the need to follow instructions or advice of veterinarians. Moreover, only $10.4 \%$ regularly relied on responses to drugs sensitivity tests when evaluating the effectiveness of antimicrobials. Overall, assessment of KAP regarding antimicrobial usage indicated that the majority of respondents had low levels of knowledge of antimicrobials, neutral rather than positive attitudes, and employed poor practices in the use of antimicrobials. The results indicate improvements in KAP could be helpful in developing more effective interventions by farmers, reduce antibiotic usage, and slow the growth of antimicrobial resistance.
\end{abstract}

Keywords: antimicrobials usage, attitudes, knowledge, practices, resistance

\section{Introduction}

Over the past few decades, antimicrobial resistance phenomenon has been increasingly accepted as an important issue imposed a large socio-economic burdens affecting both animal and human health $[6,9,24]$. Limits of drugs choosing and reduces in first line empirical treatment against bacterial infection are risked causing by an extant circumstance [11]. Nowadays, approximate of more than half of all antimicrobials produced globally are used in livestock [13]. Resistant bacteria emerged in farm production is seem to be an important source spreading to human by various means, including food chain as well as direct or indirect contacts [7, $8,21]$. Overusing of antimicrobials due to weak law enforcement, lack of drug-use monitoring and misconceptions regarding appropriate usage are denoted by means of the main contributors in resisted occurrence [1], especially those are more prevalent in low- and middle-income region, such as
South and Southeast Asia countries [15].

In Thailand, at present, the pig and poultry industries have become the nation's largest industrial livestock sectors. Chiang Mai, Lamphun and Chonburi provinces are the high density farming areas in the country, with $46.57 \%$ of the layers and $26.57 \%$ of the pigs [14]. However, baseline data on antimicrobial usage at farm level is not completed, likely an underestimate. The compliance following antimicrobial management policy is oversight. Thus, inappropriate use of antimicrobials on farm is continued to engage.

Farm owners and managers are the key decision-makers regarding the use of antimicrobials on farms, based on their knowledge, attitudes and practices (KAP) [23]. For that reason, modifying the key personal's KAP is an important potential early strategy to help preserve antimicrobial effectiveness in this era of growing resistance by appropriate using $[2,17]$. The strategy could be disseminated to policy makers and other stakeholders, to provide them with evidence on

*Corresponding author

Tel: +66-53948023, Fax: +66-53948065

E-mail: td.pakpoom@gmail.com 
which to base rules and regulations regarding in right way.

This study focused on investigation of the key personal's KAP related to antimicrobials usage on farms in the three target provinces, Chiang Mai, Lamphun and Chonburi. To the best of the authors' knowledge, no research has been done on the KAP characteristics on layer and pig farms in Thailand. Accordingly, the study attempted to develop a database served as a baseline and which could provide further insights for planning and developing strategies to promote the appropriate use of antimicrobials and control of antimicrobials resistance emerged in the areas.

\section{Materials and Methods}

\section{Study design and population}

A cross-sectional survey study was conducted in layer and pig farms in Chiang Mai, Lamphun and Chonburi provinces during the period May 2014 through February 2016. For the sample sizes, numbers of layer and pig farm owners/managers were calculated using Epi Info 7 software (Center for Disease Control and Prevention, USA). A response distribution of $80 \%$ was assumed, with a confidence interval of $95 \%$ and a margin of error of $5 \%$. The estimated minimum effective targeted sample sizes were designed to be 126 and 125 , respectively. Eighty-five of the layer farms and 75 of the pig farms were selected using a convenience sampling method from the areas of Chiang Mai and Lamphun provinces. Besides, fifty pig farms and 41 layer farms in Chonburi province are also chosen, as the similar method mentioned. The targeted farms were classified as small, medium or large scale. The size of each stratum was determined by proportionate allocation of the total number of layer and pig farms. Layer farms with 1,000 to 10,000 birds were categorized as small-scale; those with 10,001 to 50,000 birds were medium scale; and those with more than 50,000 birds were classified as large-scale farms [5]. For pig farms, livestock units, the total bodyweight $(\mathrm{kg})$ of all the pigs divided by 500 , was used to categorize the scale of those. The average bodyweight of one sow or boar, finisher and piglet were approximated on $170 \mathrm{~kg}, 60 \mathrm{~kg}$ and $12.5 \mathrm{~kg}$, respectively [19]. Farms with 6 to 59 livestock units were categorized as small-scale; those with 60 to 600 livestock units were classified as mediumscale; and those with more than 600 livestock units were classified as large-scale farms.

\section{Development of the KAP questionnaire}

Assessment of key personal's KAP is performed using a validated self-administered questionnaire. It was comprised of two main parts. Part 1 dealt with characteristics of the respondents and their farms. That consisted of 16 statements covering general demographic information, farm management, and the disease situation on the farm and farming economics. Part 2 was designed to evaluate KAP towards antimicrobial usage. Three sub-sections were composed for that part. The first subsection consisted of 11 statements intended to evaluate knowledge of antimicrobial usage and antimicrobial impacts on their farms and 6 statements to evaluate the respondents' knowledge of laws and regulations governing antimicrobial using on farms. In these subsection, respondents were asked to select among three options provided for

Table 1. Reliability analysis of attitudes statements of layer and pig farm's key persons in the study

\begin{tabular}{|c|c|c|}
\hline Attitude statement & $\begin{array}{c}\text { Total } \\
\text { correlation }\end{array}$ & $\begin{array}{c}\text { Alpha, if the } \\
\text { item was } \\
\text { deleted }\end{array}$ \\
\hline \multicolumn{3}{|l|}{ Cronbach's alpha score $=0.66$} \\
\hline 1. Antimicrobial usage for protection against diseases on farms is the most important.* & 0.286 & 0.653 \\
\hline 2. Usage of the same antimicrobial drugs for long periods of time can lead to antimicrobial resistance. & 0.340 & 0.642 \\
\hline $\begin{array}{l}\text { 3. Usage of antimicrobial drugs for non-therapeutic reasons, e.g., as a growth promoter, or for prophylactic } \\
\text { treatment cannot lead to antimicrobial resistance.* }\end{array}$ & 0.258 & 0.661 \\
\hline $\begin{array}{l}\text { 4. The use of antimicrobial drugs (such as avoparcin, chlortetracycline, oxytetracycline and spiramycin) for } \\
\text { non-therapeutic reasons (as a growth promoter) can lead to antimicrobial resistance. }\end{array}$ & 0.254 & 0.661 \\
\hline 5. Drug administration should be followed a veterinarian's instructions except in the case of non-prescription drugs. & 0.196 & 0.670 \\
\hline 6. Purchasing of antimicrobial drugs from a drug company or cooperative with a legal permit is safe. & 0.241 & 0.660 \\
\hline 7. Rational use of antimicrobial drugs can lead to reduce antimicrobial resistance. & 0.636 & 0.613 \\
\hline $\begin{array}{l}\text { 8. Inappropriate use of antimicrobial drugs can cause antimicrobial resistance, can contaminate the environment } \\
\text { and genetically transfer antimicrobial resistance to animals and humans. }\end{array}$ & 0.184 & 0.678 \\
\hline $\begin{array}{l}\text { 9. Strong enforcement of laws and regulations governing the rational use of antimicrobial drugs can lead to reduced } \\
\text { antimicrobial resistance. }\end{array}$ & 0.489 & 0.608 \\
\hline $\begin{array}{l}\text { 10. Improper farm waste management can cause antimicrobial resistance, contaminate the environment and } \\
\text { genetically transfer antimicrobial resistance to animals and humans. }\end{array}$ & 0.533 & 0.624 \\
\hline 11. The most important reason for choosing antimicrobial drugs on your farm is the economic costs and benefits.* & 0.390 & 0.632 \\
\hline
\end{tabular}

\footnotetext{
*Statement was reversed scored
} 
each statement with either "Yes", "No", or "Not Sure". The second subsection consisted of 11 statements to evaluate the attitudes of farm owners/managers toward antimicrobial use and resistance. In this section, they were provided with a five-point Likert scale ranging from "Strongly Agree" to "Strongly Disagree". The third subsection consisted of 14 statements to evaluate farmers' practices related to antimicrobial using. A four-point Likert scale with responses ranging from "Usually" to "Never" was performed. All of 3 subsections in part 2, some of the statements were represented the respectable approach for antimicrobials using; some were denoted the opposite meaning. Positive responses to a statement were assumed to indicate that the respondent felt the KAP described was accurate. On the other hand, the nega- tive statements were scored reversely.

The questionnaire was prepared in two language versions: English and Thai (the national language of Thailand). A consensus regarding the contents and wording of the questionnaire was achieved during a meeting of experts who were involved in preparation of the questionnaire. A pilot study of the questionnaire in field test was conducted with 15 farm owners/managers randomly selected from the study provinces. Reliability testing of attitude responses conducted in the pilot test was found internal consistency among the items, with a Cronbach's alpha value of 0.66 . The results (shown in Table 1) indicate that respondents were able to understand and answer the questions provided, so no further modification of the questionnaire was undertaken prior to the actual survey.

Table 2. General characteristics of participating layer and pig farm's key persons in the study

\begin{tabular}{|c|c|c|c|}
\hline \multirow{2}{*}{ Characteristics } & \multicolumn{3}{|c|}{ Numbers of participant (\%) } \\
\hline & Layer farm & Pig farm & Overall \\
\hline \multicolumn{4}{|l|}{ Sex } \\
\hline Male & $78(61.9)$ & $78(62.4)$ & $156(62.2)$ \\
\hline Female & $48(38.1)$ & $47(37.6)$ & $95(37.8)$ \\
\hline \multicolumn{4}{|l|}{ Age (yr) } \\
\hline$<30$ & $3(2.4)$ & $5(4.0)$ & $8(3.2)$ \\
\hline $30-40$ & $20(15.9)$ & $29(23.2)$ & $49(19.5)$ \\
\hline $41-50$ & $31(24.6)$ & $33(26.4)$ & $64(25.5)$ \\
\hline $51-60$ & $54(42.8)$ & $42(33.6)$ & $96(38.2)$ \\
\hline$>60$ & $18(14.3)$ & $16(12.8)$ & $34(13.5)$ \\
\hline \multicolumn{4}{|c|}{ Mean $\pm \mathrm{SD}=48.9 \pm 11.4$, Range $=16$ to 78} \\
\hline \multicolumn{4}{|c|}{ Education } \\
\hline Primary education & $66(52.4)$ & $59(47.2)$ & $125(49.8)$ \\
\hline Secondary education & $29(23.0)$ & $25(20.0)$ & $54(21.5)$ \\
\hline Diploma & $4(3.2)$ & $8(6.4)$ & $12(4.8)$ \\
\hline Bachelor's degree & $26(20.6)$ & $27(21.6)$ & $53(21.1)$ \\
\hline Over Bachelor's degree & $1(0.8)$ & $6(4.8)$ & $7(2.8)$ \\
\hline \multicolumn{4}{|l|}{ Farming experience (yr) } \\
\hline$<1$ & $3(2.4)$ & $0(0.0)$ & $3(1.2)$ \\
\hline $1-2$ & $5(4.0)$ & $2(1.6)$ & $7(2.8)$ \\
\hline $3-5$ & $5(4.0)$ & $9(7.2)$ & $14(5.6)$ \\
\hline$>5$ & $113(89.6)$ & $114(91.2)$ & $227(90.4)$ \\
\hline \multicolumn{4}{|l|}{ Farm ownership/management } \\
\hline Independent & $47(37.3)$ & $30(24.0)$ & $77(30.7)$ \\
\hline Cooperative & $18(14.3)$ & $28(22.4)$ & $46(18.3)$ \\
\hline Contract & $61(48.4)$ & $67(53.6)$ & $128(51.0)$ \\
\hline \multicolumn{4}{|l|}{ Farm registration status } \\
\hline Registered & $114(90.5)$ & $120(96.0)$ & $234(93.2)$ \\
\hline Not registered & $3(2.4)$ & $2(1.6)$ & $5(2.0)$ \\
\hline Registration in process & $9(7.1)$ & $3(2.4)$ & $12(4.8)$ \\
\hline \multicolumn{4}{|l|}{ Farm size } \\
\hline Small & $42(33.3)$ & $56(44.8)$ & $98(39.0)$ \\
\hline Medium & $71(56.4)$ & $58(46.4)$ & $129(51.4)$ \\
\hline Large & $13(10.3)$ & $11(8.8)$ & $24(9.6)$ \\
\hline \multicolumn{4}{|l|}{ Study site } \\
\hline Chiang Mai, Lamphun & $85(67.5)$ & $75(60.0)$ & $160(63.7)$ \\
\hline Chonburi & $41(32.5)$ & $50(40.0)$ & $91(36.3)$ \\
\hline
\end{tabular}




\section{Ethical considerations}

An animal care and use certificate was not required for this research because no animals were involved in the study. Participants were informed in writing about the study and its objectives in their own language. The informed consent form was explained to illiterate respondents. Only individuals who agreed to participate and who signed the informed consent form were included in the study.

\section{Data analysis}

KAP respondents' answers of individual person were scored. One mark was awarded for each correct answer and zero marks for each wrong or unsure response for the knowledge assessment. The total knowledge score was categorized into three levels using Bloom's cut off point (60-80\%): low level (less than 60\%), moderate level (60-80\%), and high level (more than $80 \%$ ). For the personal's attitude responses

Table 3. Rate of corrected responses of key personal's knowledge in the study

\begin{tabular}{|c|c|c|c|}
\hline \multirow{2}{*}{ Statement } & \multicolumn{3}{|c|}{ Numbers of personal's corrected response $(\%)$} \\
\hline & Layer farm & Pig farm & Overall \\
\hline \multicolumn{4}{|l|}{ Knowledge of antimicrobial usage } \\
\hline $\begin{array}{l}\text { 1. Antimicrobial drugs are compounds which are used for bacterial treatment and } \\
\text { control. }\end{array}$ & $51(40.5)$ & $58(46.4)$ & $109(43.4)$ \\
\hline 2. Virus and fungi are microorganisms that antimicrobials cannot cure. & $40(31.7)$ & $43(34.4)$ & $83(33.1)$ \\
\hline 3. Antimicrobial drugs are the same as drug for relief of inflammation.* & $29(23.0)$ & $36(28.8)$ & $65(25.9)$ \\
\hline $\begin{array}{l}\text { 4. Antimicrobial drugs should be stored in a secure place and in accordance with } \\
\text { the manufacturers' recommendation. }\end{array}$ & $119(94.4)$ & $121(96.8)$ & $240(95.6)$ \\
\hline $\begin{array}{l}\text { 5. Interaction among multi-antimicrobial drugs used at the same time can reduce } \\
\text { the efficacy of other antimicrobial drugs for bacterial treatment and control. }\end{array}$ & $65(51.6)$ & $80(64.0)$ & $145(57.8)$ \\
\hline $\begin{array}{l}\text { 6. Antimicrobial drug's efficacy could not be reduced belonging sub-recommended } \\
\text { dosages used.* }\end{array}$ & $55(43.7)$ & $68(54.4)$ & $123(49.0)$ \\
\hline $\begin{array}{l}\text { 7. Drug withdrawal periods should be adhered to as per the prescription to avoid } \\
\text { drug residues in meat or animal products. }\end{array}$ & $120(95.2)$ & $120(96.0)$ & $240(95.6)$ \\
\hline \multicolumn{4}{|l|}{ Knowledge of antimicrobial using consequences } \\
\hline $\begin{array}{l}\text { 8. Antimicrobial drug residues and drug resistance will occur when antimicrobials } \\
\text { are not used prudently. }\end{array}$ & $80(63.5)$ & $80(64.0)$ & $160(63.7)$ \\
\hline $\begin{array}{l}\text { 9. The non-therapeutic use of antimicrobial drugs, e.g., as a growth promoter or } \\
\text { prophylactic cannot lead to antimicrobial resistance.* }\end{array}$ & $45(35.7)$ & $55(44.0)$ & $100(39.8)$ \\
\hline $\begin{array}{l}\text { 10. Use of the same antimicrobial drugs for an extended period can cause } \\
\text { antimicrobial resistance. }\end{array}$ & $105(83.3)$ & $107(85.6)$ & $212(84.5)$ \\
\hline $\begin{array}{l}\text { 11. Rational use of antimicrobial drugs including using the proper dosage can lead } \\
\text { to reduced antimicrobial resistance. }\end{array}$ & $111(88.1)$ & $108(86.4)$ & $219(87.3)$ \\
\hline \multicolumn{4}{|l|}{ Knowledge of Acts and regulation to control antimicrobial usage } \\
\hline $\begin{array}{l}\text { 12. Thailand has laws and regulations controlling drug use, animal farms and the } \\
\text { environment. }\end{array}$ & $99(78.6)$ & $100(80)$ & $199(79.3)$ \\
\hline $\begin{array}{l}\text { 13. The non-therapeutic use of antimicrobial drugs, e.g., as a growth promoter in } \\
\text { feed for animals for meat consumption is prohibited. }\end{array}$ & $76(60.3)$ & $93(74.4)$ & $169(67.3)$ \\
\hline $\begin{array}{l}\text { 14. Mixing of chloramphenicols and nitrofurans in the feed of food animals is } \\
\text { prohibited. }\end{array}$ & $63(50.0)$ & $88(70.4)$ & $151(60.2)$ \\
\hline $\begin{array}{l}\text { 15. Drug administration other than as indicated on the label/accompanying } \\
\text { documentation is not permitted except as prescribed by a veterinarian. }\end{array}$ & $55(43.7)$ & $74(59.2)$ & $129(51.4)$ \\
\hline $\begin{array}{l}\text { 16. Antimicrobial drugs and medicated premix must be approved by or registered } \\
\text { with the competent authority. }\end{array}$ & $102(81.0)$ & $117(93.6)$ & $219(87.3)$ \\
\hline $\begin{array}{l}\text { 17. Sale and distribution of antimicrobial drugs shall only be done by persons } \\
\text { permitted to do so by law. }\end{array}$ & 107 (92.9) & $118(94.4)$ & $225(89.6)$ \\
\hline
\end{tabular}

Note: only yes answer represents the corrected responses. *Statement reverse scored. 
assessment, positive statements were scored from five marks to one mark related the ranging from "Strongly Agree" to "Strongly Disagree", while reverse scoring was used for negative statements. Total attitude scores were categorized similarly to the knowledge scores, i.e., using Bloom's cut off point (60-80\%). Attitude scores were categorized as not concerned (score less than 60\%), neutral (60-80\%) and concerned (more than $80 \%$ ). In addition, for individual's practices assessment, positive statement responses were rated from four to one mark following the range of "Usually" to "Never". However, the reverse scoring was used for negative statements as the similar calculating system mentioned. The combined Practice scores of the respondents were also categorized into three levels using Bloom's cut-off point (60-80\%), i.e., poor practice (less than $60 \%$ ), fair practice $(60-80 \%)$ and good practice (more than $80 \%$ ). Descriptive statistics were used to summarize demographic characteristics as well as the respondent's KAP. The differences of relative proportions in respondent's KAP rating between farm type (layer farms and pig farms) were analyzed using Chi square tests as appropriate [12]. The level of statistical significance was set at $p<0.05$. All data were analyzed using the Statistical Package for the Social Sciences (SPSS, USA) ver. 17.0 [18].

\section{Results}

A total of 251 individuals completed the interview questionnaire, with a male to female ratio of 1.6:1 (62.2\% male). The mean age of the participants was 48.9 years with a SD deviation of 11.4 years. The majority of the respondents were between 51 and 60 years $(38.2 \%)$. A half of them had only a primary education. Most (51.0\%) were contract farmers, while $30.7 \%$ were independent farmers and $18.3 \%$ were members of a farm cooperative. In terms of standard farm registration with the Department of Livestock Development, nearly all $(93.2 \%)$ had registered with the appropriate government agency. Most farms (51.4\%) were medium-scale, followed by small-scale $(39.0 \%)$ and large-scale $(9.6 \%)$. The majority of the respondents $(70.9 \%)$ had more than five years of farming experience. Distribution of the respondents was Chiang Mai-Lamphun provinces $63.7 \%$ and Chonburi province $36.6 \%$ (Table 2 ).

Assessment of knowledge of antimicrobials usage (Table 3 ) found that the areas with the most incorrected responses were identifying antimicrobials as being suitable for the relief of inflammation $(25.9 \%)$ and treating viral and fungal infection $(33.1 \%)$. The corrected response, that antimicrobial drug's efficacy could be reduce under the sub-recommended

Table 4. Rate of agreement of key personal's attitudes in the study

\begin{tabular}{|c|c|c|c|}
\hline \multirow{2}{*}{ Statement } & \multicolumn{3}{|c|}{ Numbers of personal's agreement (\%) } \\
\hline & Layer farm & Pig farm & Overall \\
\hline 1. Antimicrobial usage for protection against diseases on farms is the most important.* & 99 (78.6) & $86(68.8)$ & $185(73.7)$ \\
\hline $\begin{array}{l}\text { 2. Usage of the same antimicrobial drugs for long periods of time can lead to antimicrobial } \\
\text { resistance. }\end{array}$ & $102(81.0)$ & $105(84.0)$ & $207(82.5)$ \\
\hline $\begin{array}{l}\text { 3. Usage of antimicrobial drugs for non-therapeutic reasons, e.g., as a growth promoter, or for } \\
\text { prophylactic treatment cannot lead to antimicrobial resistance.* }\end{array}$ & $46(36.5)$ & $36(28.8)$ & $82(32.7)$ \\
\hline $\begin{array}{l}\text { 4. The use of antimicrobial drugs (such as avoparcin, chlortetracycline, oxytetracycline and } \\
\text { spiramycin) for non-therapeutic reasons (as a growth promoter) can lead to } \\
\text { antimicrobial resistance. }\end{array}$ & $92(73.0)$ & $75(60.0)$ & $167(66.5)$ \\
\hline $\begin{array}{l}\text { 5. Drug administration should be followed a veterinarian's instructions except in the case of } \\
\text { non-prescription drugs. }\end{array}$ & $120(95.2)$ & $98(78.4)$ & $218(86.9)$ \\
\hline $\begin{array}{l}\text { 6. Purchasing of antimicrobial drugs from a drug company or cooperative with a legal permit } \\
\text { is safe. }\end{array}$ & $107(84.9)$ & $98(78.4)$ & $205(81.7)$ \\
\hline 7. Rational use of antimicrobial drugs can lead to reduce antimicrobial resistance. & 112 (88.9) & $94(75.2)$ & $206(82.1)$ \\
\hline $\begin{array}{l}\text { 8. Inappropriate use of antimicrobial drugs can cause antimicrobial resistance, can contam- } \\
\text { inate the environment and genetically transfer antimicrobial resistance to animals and } \\
\text { humans. }\end{array}$ & $117(92.9)$ & $101(80.8)$ & $218(86.9)$ \\
\hline $\begin{array}{l}\text { 9. Strong enforcement of laws and regulations governing the rational use of antimicrobial } \\
\text { drugs can lead to reduced antimicrobial resistance. }\end{array}$ & 99 (78.6) & $87(69.6)$ & $186(74.1)$ \\
\hline $\begin{array}{l}\text { 10. Improper farm waste management can cause antimicrobial resistance, contaminate the } \\
\text { environment and genetically transfer antimicrobial resistance to animals and humans. }\end{array}$ & $113(89.7)$ & $95(76.0)$ & $208(82.9)$ \\
\hline $\begin{array}{l}\text { 11. The most important reason for choosing antimicrobial drugs on your farm is the } \\
\text { economic costs and benefits.* }\end{array}$ & $93(73.8)$ & $67(53.6)$ & $160(63.7)$ \\
\hline
\end{tabular}

Note: agree includes both strongly agree and agree responses. *Statement reversed scored. 
dosages used, was given by $49.0 \%$, while $57.8 \%$ accurately thought that using multiple antimicrobial drugs at the same time can reduce overall efficacy of bacterial treatment and control. In addition, nearly $40 \%$ of all the respondents thought that using antimicrobial drugs for non-therapeutic reasons (as a growth promoter) or as a prophylactic treatment cannot lead to antimicrobial resistance. Regarding knowledge of acts and regulations controlling antimicrobial usage, more than a haft of the respondents (51.4 to 89.6\% for almost all dimensions studied) correctly thought that the use of antimicrobials required a prescription from a veterinarian, that mixing a growth promoter in feed for food producing animals for human consumption is prohibited and that the sale and distribution of antimicrobial drugs must be done by competent authority.

Table 4 provides a summary of the attitudes of respondents toward antimicrobial usage and antimicrobial resistance. Overall, nearly two thirds of respondents agreed with the correct statements for almost all dimensions including that drug administration should be done according to the veterinarian's instructions, inappropriate use of antimicrobial drugs can cause antimicrobial resistance, improper management of farm waste management can result in antimicrobial resistance and usage of the same antimicrobial drugs for long periods can lead to antimicrobial resistance. Nevertheless, $73.7 \%$ of the respondents felt that antimicrobial usage is the most important factor in achieving disease protection on the farm, the highest rate of agreement with a false statement in this section. Additionally, $63.7 \%$ of the respondents incor- rectly believed that the primary reason for using antimicrobials on the farm are the economic costs and benefits, and $32.7 \%$ believed that using antimicrobial drugs for non-therapeutic objectives (such as growth promotion) or as a prophylactic treatment cannot lead to antimicrobial resistance, respectively.

As shown in Table 5, the highest rate of positive routine practices statements was farmers adhering to the drug withdrawal periods before sending animals for slaughter $(92.0 \%)$. The highest response for negative practices was the use of multiple antimicrobial drugs at the same time to increase effectiveness $(47.4 \%)$, followed by the use of the same antimicrobial drugs for long periods of time (45.8\%). However, only $29.5 \%$ of respondents regularly used antimicrobial drugs on their farm for prevention diseases and $24.3 \%$ used the drugs in the absence of a disease outbreak.

Overall KAP ratings are shown in Table 6. Of the 251 respondents, only $70(27.8 \%)$ had a high level knowledge of antimicrobial usage while $110(43.8 \%)$ had high a level of knowledge of antimicrobial using consequences and 108 $(43.0 \%)$ had a high level of knowledge of regulations. Only $20(8.0 \%)$ had a good concerned attitude toward antimicrobial usage, while the attitude of $138(55.0 \%)$ was neutral. Only $25(10.0 \%)$ were found to be employing good practices, while 135 (53.8\%) were following poor practices. The statistical analyses shows that differences of relative proportions in key personal's KAP rating between farm type (layer farms and pig farms) in 3 pairwise comparisons, including in the low level knowledge of regulations $(24.6 \%$ vs. $9.5 \%)$,

Table 5. Frequencies of key personal's practices in the study

\begin{tabular}{|c|c|c|c|}
\hline \multirow{2}{*}{ Statement } & \multicolumn{3}{|c|}{ Numbers of personal's routines $(\%)$} \\
\hline & Layer farm & Pig farm & Overall \\
\hline 1. Veterinarians are responsible for drugs prescriptions. & $41(32.5)$ & $74(59.2)$ & $115(45.8)$ \\
\hline 2. The farm owner/manager is the top authority for drug purchases.* & $49(38.9)$ & $52(41.6)$ & $101(40.2)$ \\
\hline 3. Prevention is the main purpose of antimicrobial use on farms.* & $24(19.1)$ & $50(40.0)$ & $74(29.5)$ \\
\hline 4. Farmers consult a veterinarian regarding the decision to use antimicrobial drugs on the farm. & $54(42.9)$ & $70(56.0)$ & $124(49.4)$ \\
\hline 5. Farmers use antimicrobial drugs in the absence of a disease outbreak.* & $31(24.6)$ & $30(24.0)$ & $61(24.3)$ \\
\hline $\begin{array}{l}\text { 6. The duration of antimicrobial drug administration follows the drug recommendations and the } \\
\text { advice of the consulting veterinarian. }\end{array}$ & $93(73.8)$ & $79(63.2)$ & $172(68.5)$ \\
\hline $\begin{array}{l}\text { 7. Farmers use multiple antimicrobial drugs at the same time to increase antimicrobial } \\
\text { efficacy.* }\end{array}$ & $64(50.8)$ & $55(44.0)$ & $119(47.4)$ \\
\hline 8. Farmers test sensitivity before choosing antimicrobial drugs for use on the farm. & $4(3.2)$ & $22(17.6)$ & $26(10.4)$ \\
\hline 9. Farmers use the same antimicrobial drugs for long periods of time on the farm.* & $54(42.9)$ & $61(88.8)$ & $115(45.8)$ \\
\hline 10. Farmers don't mix prohibited antimicrobial drugs into the feed of food producing animals. & $123(97.6)$ & $0(0.0)$ & $123(49.0)$ \\
\hline $\begin{array}{l}\text { 11. Farmers adhere to specified drug withdrawal periods before sending animals to the } \\
\text { slaughterhouse. }\end{array}$ & $116(92.1)$ & $115(92.0)$ & $231(92.0)$ \\
\hline 12. Antimicrobial drugs are stored in the proper location on the farm. & $55(43.7)$ & $116(92.8)$ & $171(68.1)$ \\
\hline 13. Farmers don't sell dead animals which have been treated with antimicrobial drugs. & $124(98.4)$ & $0(0.0)$ & $124(49.4)$ \\
\hline 14. Farmers record their use of medication on the farm. & $85(67.5)$ & $58(46.4)$ & $143(57.0)$ \\
\hline
\end{tabular}

Note: the routine work includes both usually and sometime responses. * Statement reversed scored 
Table 6. Overall rating of key personal's knowledge, attitudes and practices (KAP) in the study

\begin{tabular}{|c|c|c|c|c|}
\hline \multirow{2}{*}{ Characteristics } & Layer farm & Pig farm & Overall & \multirow{2}{*}{$p$ value } \\
\hline & n $(\%)$ & n $(\%)$ & n $(\%)$ & \\
\hline \multicolumn{5}{|c|}{ Level of knowledge of antimicrobial usage } \\
\hline Low & $56(44.4)$ & $42(33.6)$ & $98(39.0)$ & \multirow{3}{*}{0.212} \\
\hline Moderate & $38(30.1)$ & $45(35.7)$ & $83(33.0)$ & \\
\hline High & $32(25.4)$ & $38(30.1)$ & $70(27.8)$ & \\
\hline \multicolumn{5}{|c|}{ Level of knowledge of antimicrobial using consequences } \\
\hline Low & $13(10.3)$ & $18(14.2)$ & $31(12.3)$ & \multirow{3}{*}{0.395} \\
\hline Moderate & $60(47.6)$ & $50(39.6)$ & $110(43.8)$ & \\
\hline High & $53(42.0)$ & $57(45.2)$ & $110(43.8)$ & \\
\hline \multicolumn{5}{|l|}{ Level of knowledge of regulations } \\
\hline Low & $31(24.6)$ & $12(9.5)$ & $43(17.1)$ & \multirow{3}{*}{$<0.0001$} \\
\hline Moderate & $61(48.4)$ & $39(31.0)$ & $100(39.8)$ & \\
\hline High & $34(27.0)$ & $74(58.7)$ & $108(43.0)$ & \\
\hline \multicolumn{5}{|l|}{ Attitudes toward antimicrobial usage } \\
\hline Not concerned & $62(49.2)$ & $31(24.6)$ & $93(37.1)$ & \multirow{3}{*}{$<0.0001$} \\
\hline Neutral & $60(47.6)$ & $78(61.9)$ & $138(55.0)$ & \\
\hline Concern & $4(3.2)$ & $16(12.7)$ & $20(8.0)$ & \\
\hline \multicolumn{5}{|l|}{ Quality of antimicrobial use practices } \\
\hline Poor & $69(54.8)$ & $66(52.4)$ & $135(53.8)$ & \multirow{3}{*}{$<0.0001$} \\
\hline Fair & $57(45.2)$ & $34(27.0)$ & $91(36.3)$ & \\
\hline Good & $0(0.0)$ & $25(19.8)$ & $25(10.0)$ & \\
\hline
\end{tabular}

Chi square $p$ value of the differences of relative proportions in the respondent's KAP rating, each category between farm type (layer farms and pig farms).

concerning attitude toward antimicrobial usage $(3.2 \% \mathrm{vs}$. $12.7 \%$ ), and the good quality in antimicrobial using practices $(0 \%$ vs. $19.8 \%)$, respectively.

\section{Discussion}

The KAP of farm's key personal, farm owners or managers were evaluated in this study. Many respondents incorrectly considered antimicrobials to be the same as other drugs for the relief of inflammation. Back to the basic knowledge, inflammation is one of the body immune responses against trauma or foreign invasion turning out to be harmful [22]. Antimicrobials overcome an infection by eliminating or controlling of bacterial growth, advising that it could be played a role in limiting the inflammatory response [16]. Because of this, non-medical practitioners are often misunderstood for the context. However, the proportion of respondents who thought antimicrobials are effective for viral and fungal infection $(66.9 \%)$ was greater than the figures reported for Europe and the USA, with the levels of 54\% and $55 \%$, respectively $[3,12]$. Some people were generally more familiar with the antimicrobial's trade names of than the generic names, suggesting that the brands are efficient in promoting the products. Another possible reason for the inadequacy of corrected knowledge about antimicrobials in these areas could be due to the use of the generic term "germ" which was normally used during counseling or in veterinarian advice given to the farm owner/manager rather than using the correct microbiological terms "bacteria", "virus" and "fungi" [17]. In addition, over half of the respondents wrongly understood that antimicrobial administration can be reduced from recommended dosage without reducing efficacy and more than $60 \%$ had the misconception that using antimicrobial drugs for non-therapeutic purposes, e.g., as a growth promoter, or for preventive treatment cannot result in antimicrobial resistance. Most of them assumed that it could be used in disease-free area or disease-free period. In overall of knowledge assessment, erroneous knowledge was greater among layer farm owners/managers than their pig farm counterparts.

Regarding attitudes toward antimicrobial usage and resistance, more than $70 \%$ of respondents wrongly believed that using antimicrobials for protection against disease is more important than intensive biosecurity and more than $60 \%$ considered the economic cost and benefits are the first reason making judgments about antimicrobials application. Overall, the concern levels in antimicrobial resistance were relatively low. Generally, respondents worried less about their animals' health and antimicrobial resistance than they did about financial issues. This study suggests that both layer and pig farm owners/managers, especially independent farms, should be made more aware of antimicrobial resistance, its consequences and its causes. In other studies, financial policy measures were evaluated positively by farmers; financial compensation, bonuses and punishments were considered to be the most effective means of reducing antimicrobial usage [17]. 
The efforts should be made to increase farmers' awareness that biosecurity is of major importance in reducing the incidence of diseases and antimicrobial resistance problems [4, 10].

More than $80 \%$ of respondents were aware that administration of antimicrobials on farms should be based on prescriptions from veterinarians, but they generally disregarded that in practice. In Thailand, the National Bureau of Agricultural Commodity and Food Standards (ACFS) issued a Code of Practice for Control of Use of Veterinary Drugs [20], which describes good practices in the use of veterinary drugs for food producing animals which avoid excessive use. The code also sets maximum residue limits for veterinary drugs in animals, animal produce and animal products for human consumption. Farm registration certification by the Department of Livestock Development includes the requirement that a licensed veterinarian be available and for the implementation of agricultural standards for Good Agricultural Practices [19]. Even with appropriate regulations for the control of antimicrobial usage on farms, those regulations cannot be enforced on all farms. The situation is exacerbated where there is weak law enforcement. Additionally, drug sensitivity testing prior to selecting antimicrobial drugs for use on the farm is necessary for effective treatment and disease control. In this study, however, only $10 \%$ of the respondents indicated that they usually follow this practice, a further indication that farmers have inaccurate perceptions and exhibit inappropriate behavior regarding antimicrobial use.

The overall KAP of layer and pig farm owners/managers regarding antimicrobial usage indicates that the majority of respondents had low levels of knowledge, neutral attitudes and poor practices related to antimicrobial usage. This is particularly true of layer farmers who not only had low levels of knowledge regarding usage, but who were generally not concerned about microbial resistance and employed less appropriate practices than did pig farmers $(p<0.0001)$. This difference suggests that special emphasis should be placed on making layer farmers more aware about antimicrobial usage and resistance.

This study has several limitations. First, as it was conducted only with layer farms with more than 1,000 birds and 6 different pig farms, the results may not be widely generalizable. As a convenience sampling method was used in this study, so there is a possibility of selection bias. As with other similar questionnaire surveys, the data obtained from this questionnaire survey was self-reported information which depends heavily on both the honesty and the recall ability of the respondents, as well as their understanding of the individual questions.

Analysis of the overall KAP of respondents regarding antimicrobial usage found that the majority had low levels of knowledge, neutral attitudes and employed poor antimicrobial practices. Such misconceptions, wrong beliefs and inappropriate practices can be a significant contributing factor in the cyclical increase in antibiotic resistance. An understanding of current KAP levels and their underlying causes could potentially be used to develop more effective interventions in policy making, in providing appropriate farm-specific advice, and in encouraging suitable microbial use practices on farms, e.g., educating farmers on strategies to minimize antimicrobial resistance. Key to promoting appropriate antimicrobial usage on farms is veterinarians, who, because of their existing good reputation among farmers, are ideally suited to act as a channel for informing farmers about antimicrobial resistance and the correct application of antimicrobials. It is hoped that the dissemination of this information to policy makers and stakeholders may be used as a basis for developing policies and regulations related to the appropriate use of antimicrobials on farms.

\section{Acknowledgments}

The authors would like to express our sincere thanks to the International Development Research Centre (Canada) who provided funding support for this project (No. 106915). The author also would like to thank Dr. Chongchit and Dr. G Lamar Robert for their help in preparing this report.

\section{References}

1. Boonyasiri A, Tangkoskul T, Seenama C, Saiyarin J, Tiengrim S, Thamlikitkul V. Prevalence of antibiotic resistant bacteria in healthy adults, foods, food animals, and the environment in selected areas in Thailand. Pathog Glob Health 2014, 108, 235-245.

2. Belongia EA, Schwartz B. Strategies for promoting judicious use of antibiotics by doctors and patients. BMJ 1998, 317, 668-671.

3. Belongia EA, Naimi TS, Gale CM, Besser RE. Antibiotic use and upper respiratory infections: a survey of knowledge, attitudes, and experience in Wisconsin and Minnesota. Prev Med 2002, 34, 346-352.

4. Casal J, De Manuel A, Mateu E, Martín M. Biosecurity measures on swine farms in Spain: perceptions by farmers and their relationship to current on-farm measures. Prev Vet Med 2007, 82, 138-150.

5. Delgado CL, Narrod CA, Tiongco MM. Policy, Technical, and Environmental Determinants and Implications of the Scaling-Up of Livestock Production in Four Fast-Growing Developing Countries: A Synthesis. Final Research Report of Phase II. Annex I.IV.4.3. Food and Agricultural Organization of the United Nations (FAO), Rome, 2003.

6. European Food Safety Authority (EFSA), European Centre for Disease Prevention and Control (ECDC). The European Union Summary Report on antimicrobial resistance in zoonotic and indicator bacteria from humans, animals and food in 2011. EFSA J 2013, 11, 3196.

7. Friedman DB, Kanwat CP, Headrick ML, Patterson NJ, Neely JC, Smith LU. Importance of prudent antibiotic use on dairy farms in South Carolina: a pilot project on farmers' knowledge, attitudes and practices. Zoonoses Public Health 2007, 54, 366-375.

8. Foley SL, Lynne AM. Food animal-associated Salmonella challenges: pathogenicity and antimicrobial resistance. J Anim 
Sci 2008, 86, E173-187.

9. Gandra S, Barter DM, Laxminarayan R. Economic burden of antibiotic resistance: how much do we really know? Clin Microbiol Infect 2014, 20, 973-980.

10. Garforth CJ, Bailey AP, Tranter RB. Farmers' attitudes to disease risk management in England: a comparative analysis of sheep and pig farmers. Prev Vet Med 2013, 110, 456-466.

11. Giguère S, Prescott JF, Dowling PM. Antimicrobial Therapy in Veterinary Medicine. 5th ed. pp. 3-10, Wiley-Blackwell, Ames, 2013.

12. Grigoryan L, Burgerhof JGM, Degener JE, Deschepper F, Lundborg CS, Monnet DL, Monnet DL, Scicluna EA, Birkin J, Haaijer-Ruskamp FM; SAR Consortium. Attitudes, beliefs and knowledge concerning antibiotic use and selfmedication: a comparative European study. Pharmacoepidemio Drug Saf 2007, 16, 1234-1243.

13. Guardabassi L, Jensen LB, Kruse H. Guide to Antimicrobial Use in Animals. pp. 102-142, Blackwell, Ames, 2008.

14. Information and Communication Technology Center (TH). Information for farmers in the livestock sector in 2013. Department of Livestock Development, Bangkok, 2013.

15. Kang CI, Song JH. Antimicrobial resistance in Asia: current epidemiology and clinical implications. Infect Chemother 2013, 45, 22-31.

16. Labro MT. Antibiotics as anti-inflammatory agents. Curr Opin Investig Drugs 2002, 3, 61-68.

17. Ling Oh A, Hassali MA, Al-Haddad MS, Syed Sulaiman SA, Shafie AA, Awaisu A. Public knowledge and attitudes towards antibiotic usage: a cross-sectional study among the general public in the state of Penang, Malaysia. J Infect Dev Ctries 2011, 5, 338-347.

18. Mehta CR, Patel NR. Exact Tests. In: SPSS Exact Tests 7.0 for Windows. pp. 11-37, SPSS, Chicago, 1996.

19. National Bureau of Agricultural Commodity and Food Standards, Ministry of Agriculture and Cooperatives. Good agricultural practice for pig farm; Thai Agricultural Standard, TAS 6403-2009. Royal Gazette, Bangkok, 2009.

20. National Bureau of Agricultural Commodity and Food Standards. Ministry of Agriculture and Cooperatives. Code of Practice for Control of the Use of Veterinary Drugs; Thai Agricultural Standard, TAS 9032-2009. Royal Gazette, Bangkok, 2009.

21. Patchanee $\mathbf{P}$, Tadee $\mathbf{P}$, Arjkumpa O, Love D, Chanachai K, Alter T, Hinjoy S, Tharavichitkul P. Occurrence and characterization of livestock-associated methicillin-resistant Staphylococcus aureus in pig industries of northern Thailand. J Vet Sci 2014, 15, 529-536.

22. Ricciotti E, FitzGerald AG. Prostaglandins and inflammation. Arterioscler Thromb Vasc Biol 2011, 31, 986-1000.

23. Willock J, Deary IJ, McGregor MM, Sutherland A, Edwards-Jones G, Morgan O, Dent B, Grieve R, Gibson G, Austin E. Farmers' attitudes, objectives, behaviors, and personality traits: the Edinburgh study of decision making on farms. J Vocat Behav 1999, 54, 5-36.

24. World Health Organization (WHO). WHO Global Strategy for Containment of Antimicrobial Resistance. WHO, Geneva, 2001 